\title{
EFFECTIVE METHOD FOR DETERMINING ENVIRONMENTAL LOADS ON SUPPORTING STRUCTURES FOR OFFSHORE WIND TURBINES
}

\author{
Paweł Dymarski ${ }^{1}$, Assoc. Prof. \\ Ewelina Ciba ${ }^{1}$, Ms. C. \\ Tomasz Marcinkowski² ${ }^{2}$ Ph. D. \\ 1) Gdańsk Univeristy of Technology, Poland \\ 2) Maritime Institute in Gdańsk, Poland
}

\begin{abstract}
This paper presents a description of an effective method for determining loads due to waves and current acting on the supporting structures of the offshore wind turbines. This method is dedicated to the structures consisting of the cylindrical or conical elements as well as (truncates) pyramids of polygon with a large number of sides (8 or more). The presented computational method is based on the Morison equation, which was originally developed only for cylindrically shaped structures. The new algorithm shown here uses the coefficients of inertia and drag forces that were calculated for non-cylindrical shapes. The analysed structure consists of segments which are truncated pyramids on the basis of a hex decagon. The inertia coefficients, CM, and drag coefficients, CD, were determined using RANSE-CFD calculations. The CFD simulations were performed for a specific range of variation of the period, and for a certain range of amplitudes of the velocity. In addition, the analysis of influence of the surface roughness on the inertia and drag coefficients was performed. In the next step, the computations of sea wave, current and wind load on supporting structure for the fifty-year storm were carried out. The simulations were performed in the time domain and as a result the function of forces distribution along the construction elements was obtained. The most unfavourable distribution of forces will be used, to analyse the strength of the structure, as the design load.
\end{abstract}

Keywords: offshore wind turbine, support structure, Morison force coefficients, CFD, sea wave statistics, Baltic Sea

\section{INTRODUCTION}

The calculation method presented here has been developed within the tasks of the research project AQUILO under the full name "Development of methods for the selection of the type of support structure for offshore wind turbine in Polish sea areas".

The purpose of the task, in which this research was implemented, was to design a support structure in a given area in the Polish economic zone of the Baltic Sea. Within this project, four types of structures will be analysed: a gravity base, a tripod with piles foundation, a gravity tripod and a deep water monopile.

One of the key issues that needs to be addressed in the design of this type of construction is the determination of the hydrodynamic forces acting on the object. Such forces, along with interactions from the seabed and from the wind create a system acting on the supporting structure. This system of acting forces being due to the extreme sea and weather conditions is used to determine the dimensions of the main structural elements of the construction and is based on strength analysis.
There are three main types of methods used to determine the hydro dynamical interactions:

- approximate calculation methods, based on the coefficients for hydro mechanical forces,

- accurate computational methods - RANSE-CFD

- experimental methods (based on the method of Froude).

At an early stage of the design process, the approximate methods are most frequently used and usually are very effective. It is of a great importance that the error of such primary computations is not too large. The authors of this article decided to develop a method of calculation based on the Morison equation [1].

The Morison equation is mainly used to determine the forces acting on objects of cylindrical shape, and such have been investigated experimentally in a wide range of flow parameters. Graphs of the coefficients of forces are available $[1,2,3]$. Due to the fact, that the gravity base type structure has a base made up of segments which cannot be approximated as cylindrical, the authors decided to use RANSE-CFD method in order to calculate the force coefficients of these elements. 


\section{OBJECT OF THE ANALYSIS}

The aim of the work was to develop an efficient computational method for determining loads from waves and currents acting on the supporting structures for offshore wind turbines and determination of the maximum load the hydro mechanical impact acting on the structure. The subject of the analysis was the gravity base and this article shows the step-by-step calculation process for this structure.

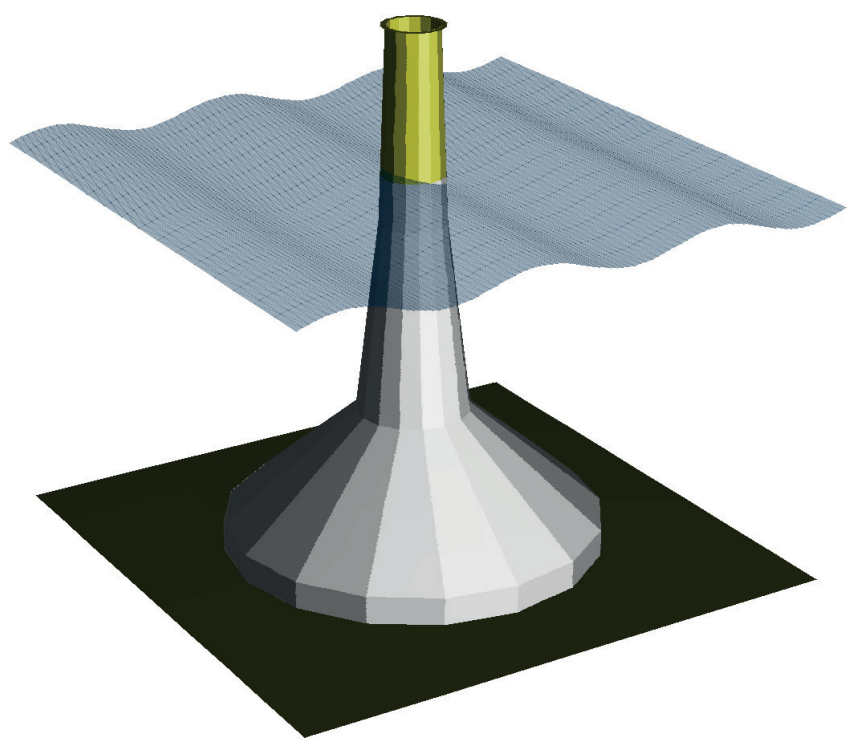

Fig. 1a. Three types of supporting structures, that were analysed in the framework of the project - Gravity base

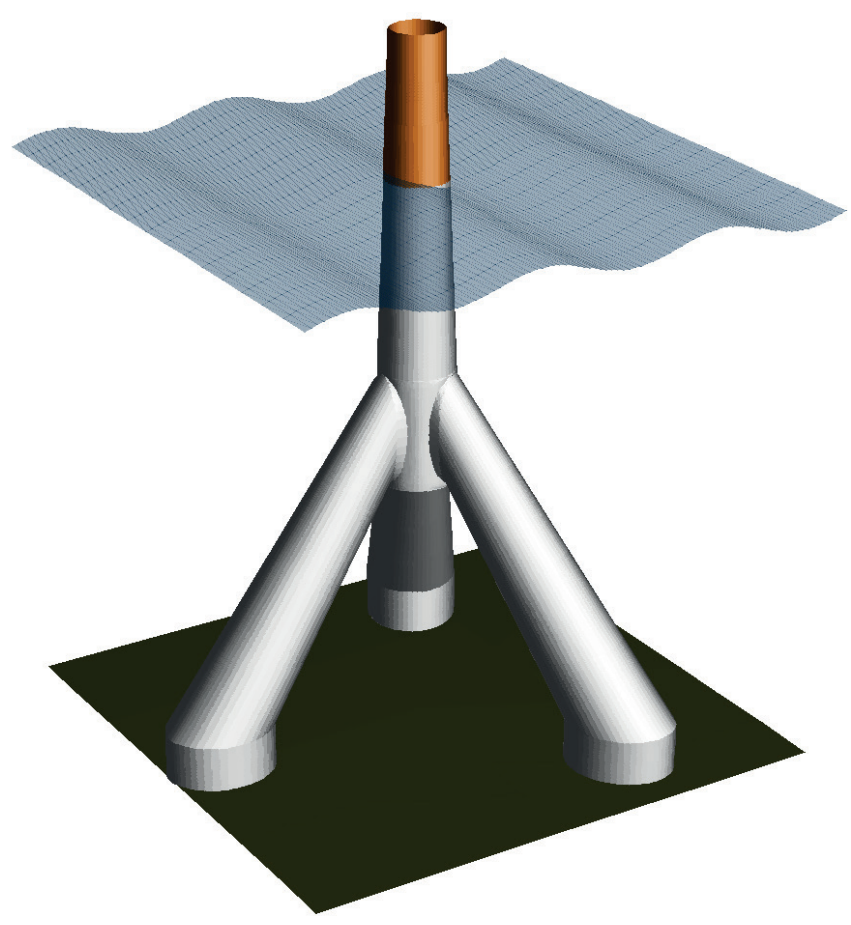

Fig. 1b. Three types of supporting structures, that were analysed in the framework of the project - Gravity tripod

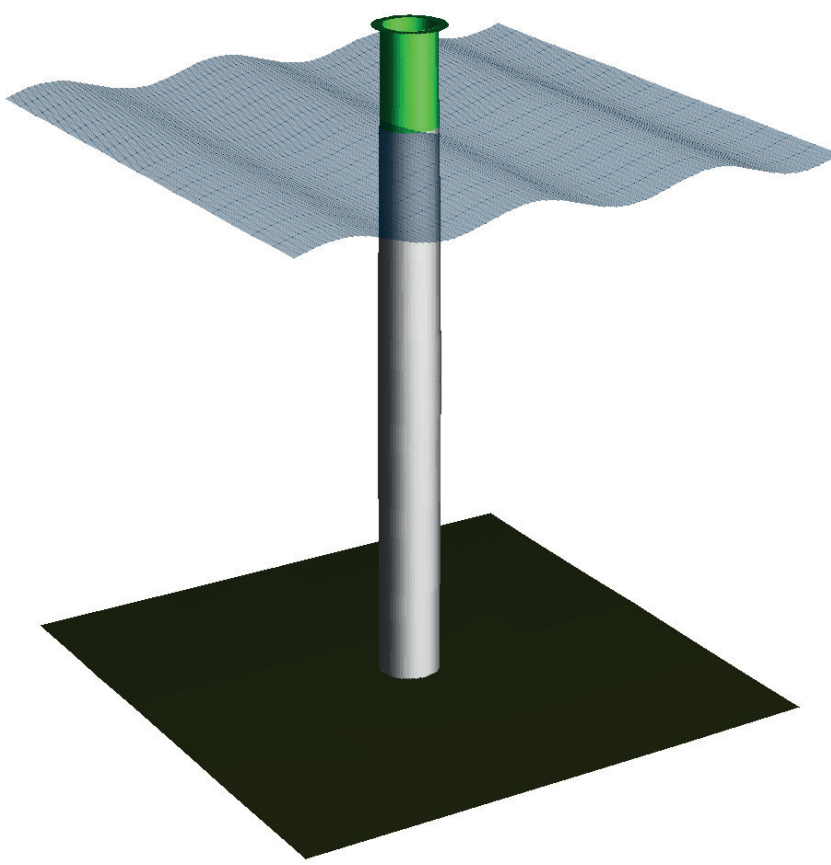

Fig. 1c. Three types of supporting structures, that were analysed in the framework of the project - Monopile

\section{THE GRAVITY BASE STRUCTURE DESCRIPTION}

The chosen support structure is a gravity base structure, the geometry of which is composed of segments of prismatic or truncated pyramid with a basis of regular hex decagon. The exact dimensions are given in Table 2 , and visualization of the structure is shown in Figure 1a.

The construction material that was chosen is steel. The interior of the structure up to a height of $\mathrm{z}=25 \mathrm{~m}$ above the seabed is to be filled in with ballast (pulp mud).

\section{CALCULATION METHOD}

\section{THE MORISON EQUATION}

The total hydro mechanical force that acts on the motionless body, which is placed in a fluid of unsteady, unidirectional flow, can by expressed by [1]:

$$
F=\frac{1}{2} C_{D} \rho A_{p}|U| U+\rho V_{b}\left(1+C_{a}^{\prime}\right)\left(\frac{\partial U}{\partial t}+U \frac{\partial U}{\partial x}\right)
$$

Where $A_{p}$ is the projected area of the body on a plane normal to the direction of the flow, $\mathrm{V}_{\mathrm{b}}$ is the volume of the body, $\mathrm{C}_{\mathrm{D}}$ and $\mathrm{C}_{\mathrm{a}}$ are the drag and added mass coefficients, $\mathrm{U}$ is the velocity and $\rho$ is the water density.

Coefficients $\mathrm{C}_{\mathrm{a}}$ and $\mathrm{C}_{\mathrm{D}}$ depend on time, geometry of the body, Reynolds number $\mathrm{R}_{\mathrm{e}}$ and the parameters describing the history of the flow (for example the amplitude and the period of the velocity variation). In practice, they are plotted 
as functions of Keulegan-Carpenter number $\mathrm{K}_{C}$ and so called $\beta=\mathrm{Rn} / \mathrm{K}_{\mathrm{C}}$ coefficient, which was proposed by Sarpkaya [1].

Morison equation is a simplified version of equation (1), where it is assumed, that the term in equation: $\mathrm{dU} / \mathrm{dt}$ can be as approximated by $\partial \mathrm{U} / \partial \mathrm{t}$, hence:

$$
F=\frac{1}{2} \rho C_{D} A_{p}|U| U+\rho C_{M} V_{b} \frac{\partial U}{\partial t}
$$

where:

$\mathrm{C}_{\mathrm{M}}=1+\mathrm{C}_{\mathrm{a}}$, and $\mathrm{C}_{\mathrm{a}}$ is an time averaged value of $\mathrm{C}_{\mathrm{a}}$.

The above equation is used for the calculations of cylindrical shapes. When the movement of fluid particles caused by the waves is to be dealt with, this equation can be used when the cylinder diameter is not greater than about $20 \%$ of wave length $\lambda$.

Coefficients $\mathrm{C}_{\mathrm{M}}$ and $\mathrm{C}_{\mathrm{D}}$ can be obtained from model tests. Sarpkaya $[1,2]$ carried out a systematic study, based on which characteristics of coefficients $C_{M}$ and $C_{D}$ for a cylindrical shape as a function of $K_{C}, \beta$ and relative roughness $k_{r} / D$ were derived. Values of these coefficients for other geometries are also available in the literature $[1,3]$.

\section{THE METHOD FOR DETERMINING THE $\mathrm{C}_{M}$ AND C $_{\mathrm{D}}$ WITH CFD}

Determination of the coefficient of the hydro mechanical reaction by CFD calculations is no different in terms of methodology to the experimental method conducted in the U-tube tank $[1,2]$. The calculations are performed in the rectangular shaped tunnel, in which by means of suitably selected boundary conditions, a flow with the sinusoidal velocity is generated:

$$
U(t)=U_{a} \sin (\omega t)
$$

In this case, the Morison equation can be written in the following way:

$$
F=\frac{1}{2} \rho C_{D} A_{p} U_{a}^{2}|\sin (\omega t)| \sin (\omega t)+\rho C_{M} V_{b} U_{a} \omega \cos (\omega t)
$$

In the above equation the first term, representing the drag force, is proportional to $\sin ^{2}(\omega t)$. The modulus of this force reaches the maximum for $\omega t=1 / 2 \pi, 3 / 2 \pi$, ..., while the whole term equals zero for $\omega t=0, \pi, 2 \pi, \ldots$. The second term of the equation is the force of inertia, which is proportional to the cosines function $\cos (\omega \mathrm{t})$. When the modulus of the drag force reaches its maximal value, the inertia force equals to zero, whereas when the resistance force is zero, the modulus of the inertia force reaches its maximum value. This principle allows us to determine the coefficient of forces with the use of the following formulas:

$$
\begin{aligned}
& C_{M}=\frac{F}{\rho V_{b} U_{a} \omega} \text { for } \omega \mathrm{t}=0, \pi, 2 \pi, \ldots \\
& C_{D}=\frac{2 F}{\rho A_{p} U_{a}^{2}} \quad \text { for } \omega \mathrm{t}=1 / 2 \pi, 3 / 2 \pi, \ldots
\end{aligned}
$$

Another, more advanced method is to search, through the optimization, for the coefficients $\mathrm{C}_{\mathrm{D}}$ and $\mathrm{C}_{\mathrm{M}}$, so that the "theoretical" function $\mathrm{F}(\mathrm{t})$ agrees with the one obtained by advanced CFD calculation.

Figure 11 shows a sample course of the function $\mathrm{F}(\mathrm{t})$ with indicated value of that is used for calculation of the $\mathrm{C}_{\mathrm{M}}$ and $\mathrm{C}_{\mathrm{D}}$, where $|U|=U_{a}$ or $\mathrm{U}=0$, because then $|\partial U / \partial t|=[\partial U / \partial t]_{a}$.

\section{THE USE OF MORISON EQUATION FOR CALCULATION OF THE IMPACT OF THE UNSTEADY AND NON- UNIFORM FLOW ON THE SUPPORT STRUCTURE. THE GENERAL FORM}

In the previously presented equations, it was assumed, that the velocity vector is perpendicular to the axis of the cylinder and the velocity field is uniform. In the general case, for example, when dealing with the velocity field appearing in the wave motion, the velocity field is not uniform, and the direction of flow (and acceleration) is changeable. The geometry of the structure varies as well. Therefore, the force acting on the section of a structure element needs to be determined using the general formula:

$$
\Delta \mathbf{F}=\left(\frac{1}{2} \rho C_{D} D\left|\mathbf{U}_{n}\right| \mathbf{U}_{n}+\frac{1}{4} \pi D^{2} \rho C_{M} \frac{\partial}{\partial t} \mathbf{U}_{n}\right) \Delta s(7)
$$

Vector of velocity normal to longitudinal axis of the element of structure:

$\mathrm{U}_{\mathrm{n}}=\mathrm{U}-\left(\mathrm{U} \cdot \mathrm{e}_{\mathrm{s}}\right) \mathrm{e}_{\mathrm{s}}$, where: $\mathrm{U}$ velocity vector and $\mathrm{e}_{\mathrm{s}}$ is a unit vector tangent to the axis of the structure, $\Delta s$ is a length of section of element in which the hydrodynamic force is calculated, $\mathrm{D}$ is a diameter of the section (or the longest diagonal if the section is a polygon). It is assumed, that $\mathrm{C}_{\mathrm{M}}$ and $C_{D}$ coefficients are a function of $K_{c}, \beta$ and the geometry of the section (and adjacent sections).

The value of the force acting on the element can be therefore determined as an integral:

$$
\mathbf{F}=\int_{0}^{s}\left(\frac{1}{2} \rho C_{d} D\left|\mathbf{U}_{n}\right| \mathbf{U}_{n}+\frac{1}{4} \pi D^{2} \rho C_{m} \frac{d}{d t} \mathbf{U}_{n}\right) d s
$$

\section{DETERMINATION OF THE VELOCITY FIELD DUE TO WAVES AND CURRENTS}

So far, we have assumed, that the velocity field is a known quantity, but just determining velocity field is not a simple task. The Maritime Institute in Gdańsk analysed the hydro meteorological data for a particular sea area and performed long-term statistical calculations $[7,8]$, based on which a set of basic parameters of the waves and sea current was obtained, Figure 2, 3. The results of WAM hindcast numerical modelling $[9,10]$ of Baltic Sea were used to calculate wave field parameters. These parameters provided materials for long-term statistical analysis. 


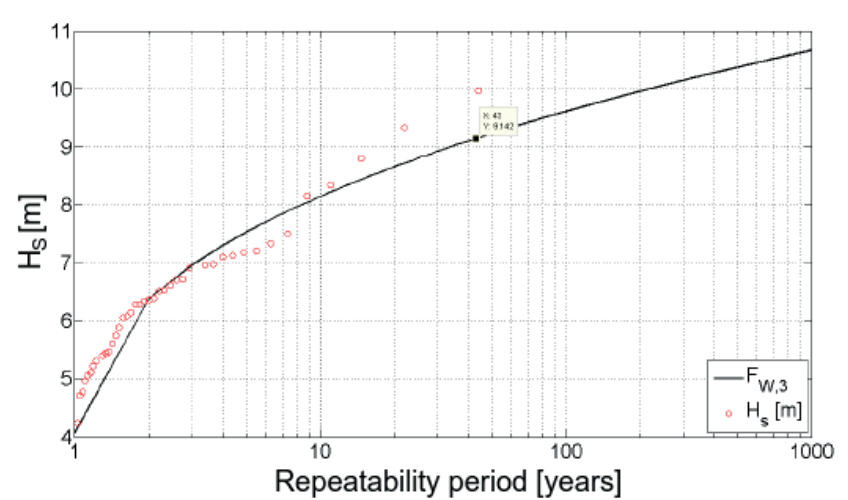

Fig. 2. Significant wave height HS as a function of return period. Weibull distribution for location: 7,750 E, 55,50 N (Baltic Sea - Polish economic zone)

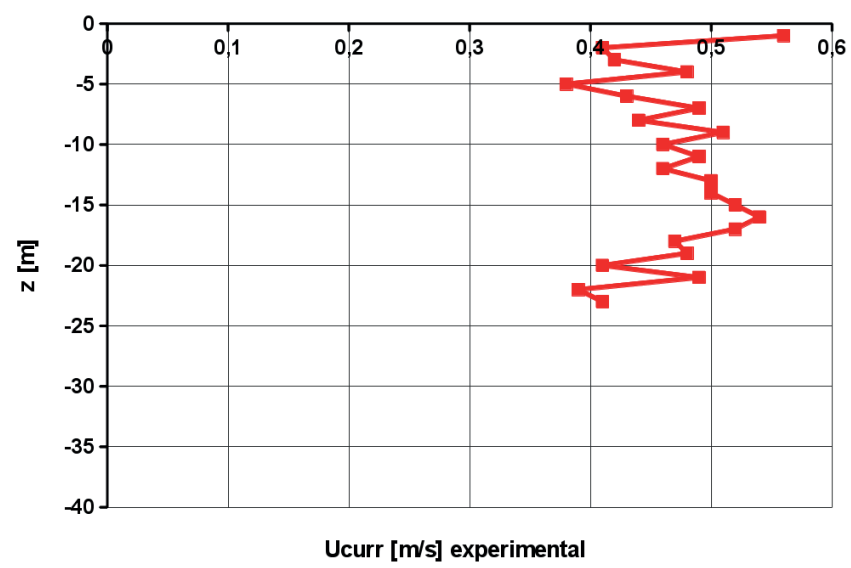

Fig. 3. Sea current velocity distribution as a function of depth. The results of measurements in the Baltic Sea during extreme storm

In this project, it was assumed, that the life time of the structure will reach 30 years with an optional extension of another 20 years, therefore, the analysis assumed parameters of the storm that happens once in 50 years. Velocities of the sea currents in the Baltic are relatively small. To calculate the desired parameters in the project, it was assumed, that the velocity of the sea current at the surface water is $\mathrm{U}_{\text {curr }}(0)=0.45 \mathrm{~m} / \mathrm{s}$, which is the velocity in the relevant reservoir that appears once in 50 years .

The velocity vector as a function of depth can be approximated to the following form:

$$
\mathbf{U}_{\text {curr }}(z)=\mathbf{e}_{\text {curr }}\left(1+\frac{z}{d}\right)^{\frac{1}{7}} U_{\text {curr }}(0)
$$

where:

$\mathrm{d}$ is the water depth, $\mathrm{z}$ is a vertical coordinate.

Sea current direction indicated by the unit vector $\mathrm{e}_{\text {curr }}$ is consistent here with the direction of the waves. Both phenomena are caused by the wind.

On the basis of statistical parameters: peak period $\mathrm{T}_{\mathrm{p}}$ and significant wave height $\mathrm{H}_{\mathrm{s}}$ the spectrum of sea waves in the form of the JONSWAP spectrum [4, 3] was reconstructed. The peak shape parameter $\gamma$ was calculated based on the recommendations of DNV [3]. The spectrum of waves can be thus approximated by a function:

$$
S_{J}(\omega)=A_{\gamma} \frac{5}{16} H_{S}^{2} \omega_{p}^{4} \omega^{-5} \exp \left(-\frac{5}{4}\left(\frac{\omega}{\omega_{p}}\right)^{-4}\right)^{\exp \left(-0.5\left(\frac{\omega-\omega_{p}}{\sigma \omega_{p}}\right)^{2}\right)}
$$

Where:

$\omega_{\mathrm{p}}=2 \pi / \mathrm{T}_{\mathrm{p}}$ is circular spectral peak frequency; $\boldsymbol{\sigma}=0.07$ for $\omega \leq \omega_{p}$ and $\sigma=0.09$ for $\omega \geq \omega_{p}$ spectral width parameter $\mathrm{A}_{\gamma}=1-0.287 \ln (\gamma)$ is a normalizing factor,

Figure 4 presents the distribution of the spectrum of waves for specific set of data, whereas Figure 5 presents the function of the sea current velocity.

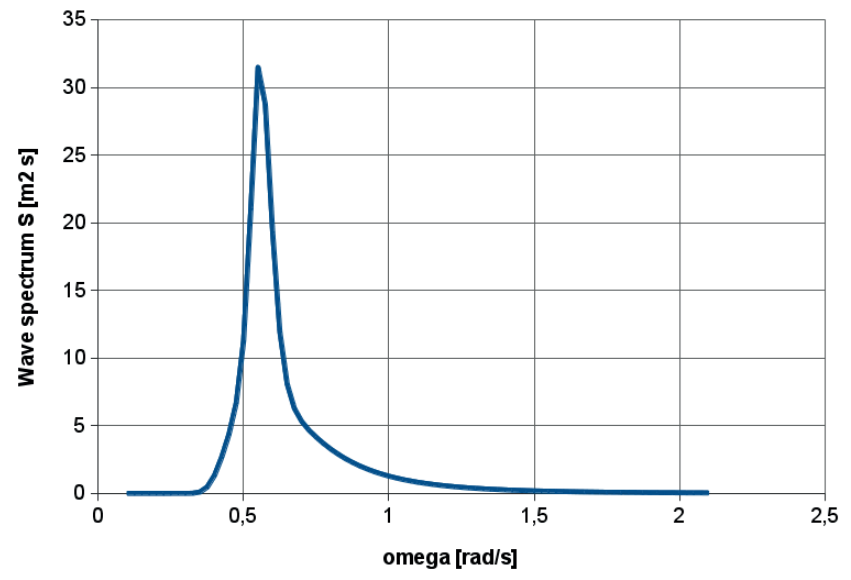

Fig. 4. Wave spectrum JONSWAP for the 50-year storm: $T_{p}=11.3 \mathrm{~s}$; $H_{s}=9.01 \mathrm{~m} ; \gamma=4.14$

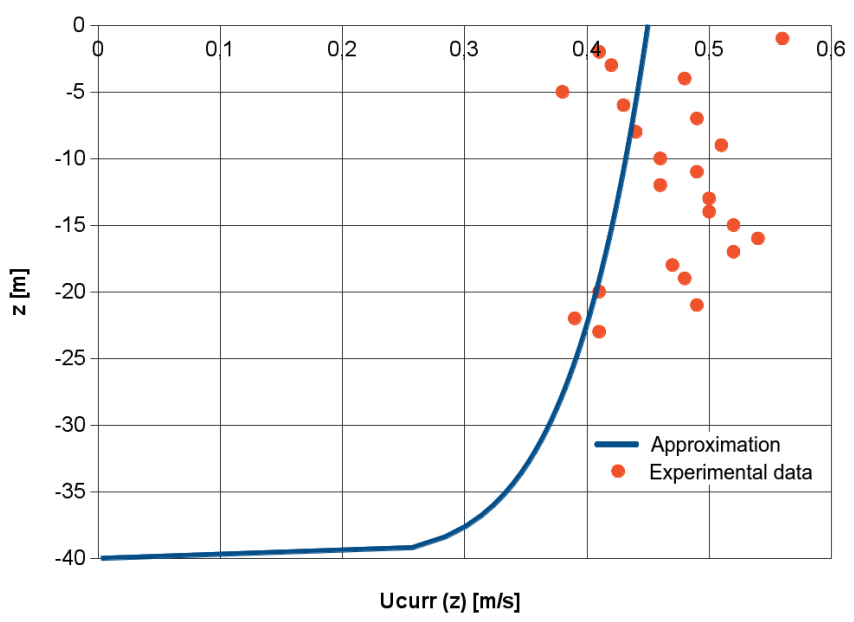

Fig. 5. Approximation of the current velocity profile for the 50-year storm

On the basis of a specific spectrum of waves, an irregular wave was generated (randomly). Due to the fact, that the depth of the reservoir is $\mathrm{d}=40 \mathrm{~m}$ and a peak period of the wave is greater than $11 \mathrm{~s}$, the chosen wave model was the second order Stokes one. Velocity field in the wave motion in the Stokes model is described as a series. This series is obtained 
by replacing the graph of a continuous spectrum of waves with the discrete graph of a finite width of the "bars" $\delta \omega$.

$$
\mathbf{U}_{\text {wave }}=\sum_{i} \mathbf{u}_{i}
$$

where the term of series $u_{i}=u\left(\omega_{i}\right)$ is obtained from:

$$
\mathbf{u}_{i}=\omega_{i}^{2} H_{i}\left\{\frac{1}{2 \sinh \left(k_{i} d\right)}\left[\begin{array}{c}
\cosh \left[k_{i}(d+z)\right] \sin \left(\theta_{i}\right) \\
\sinh \left[k_{i}(d+z)\right] \cos \left(\theta_{i}\right)
\end{array}\right]+\frac{3}{8} \frac{k_{i} H_{i}}{\sinh ^{4}\left(k_{i} d\right)}\left[\begin{array}{c}
\cosh \left[2 k_{i}(d+z)\right) \sin \left(2 \theta_{i}\right) \\
\sinh \left[2 k_{i}(d+z)\right] \cos \left(2 \theta_{i}\right)
\end{array}\right]\right\}
$$

Where:

$H_{i}=\sqrt{8 S\left(\omega_{i}\right) \delta \omega}$ is a height of $\mathrm{i}$-th wave; $\mathrm{k}_{\mathrm{i}}=2 \pi / \lambda_{\mathrm{i}}$ - wave number; $\theta_{\mathrm{i}}=\mathrm{k}_{\mathrm{i}} \mathrm{x}-\omega_{\mathrm{i}} \mathrm{t}+\varepsilon_{\mathrm{i}}$.

Value $\varepsilon_{\mathrm{i}}$ takes a random value in the range of 0 to $2 \pi$. Subsequent values of circular frequency are defined as follows: $\omega_{i+1}=\omega_{i}+\delta \omega$.

The resulting velocity field is a sum of the sea current velocity and of the velocity field due to wave:

$$
\mathrm{U}=\mathrm{U}_{\text {curr }}+\mathrm{U}_{\text {wave }}
$$

\section{IMPLEMENTATION OF CFD CALCULATIONS TO DETERMINE THE $\mathrm{C}_{\mathrm{M}}$ AND $C_{D}$ COEFFICIENTS}

The purpose of the CFD calculations was primarily to determine the coefficients for the elements of a shape other than cylindrical. The fact that the geometry is based on a hex decagon is not critical in this case. The hex decagonal prism can be treated as a cylinder. What is of importance is the fact, that the size of the polygon (its diagonal) is changing rapidly with height above the seabed $\mathrm{z}$.

Flow around such geometry, and particularly around the segments of r1, r2 and r3 (Figure 12) is three dimensional, therefore there are no tables or graphs available that can be used, describing the characteristic $\mathrm{C}_{M}$ and $\mathrm{C}_{\mathrm{D}}$, in a function of $\mathrm{K}_{\mathrm{C}}$ and the roughness of the surface. Wherein, when the Reynolds number takes the value of the order of $10^{7}$ or higher, the impact of the $\beta$ factor is minimal (Figure 6,7).

Moreover, as was described previously (section 3.2), the traditional method of determination of the $C_{D}$ and $\mathrm{C}_{\mathrm{M}}$ coefficients are model tests in the $\mathrm{U}$-tube tank. In the measuring area of the tank, the fluid flow is homogeneous (in space), but unsteady. The function of velocity in the time domain is a sinusoid.

The CFD model was built this way, to match the flow in the measuring area of a U-tube tank. The height of the computational domain is equal to the water depth, therefore, only a flow around the submerged part of the structure is modeled. The flow velocity at the inlet and outlet of the domain is specified as a sinusoidal function (in time), therefore the single test case can be determined by two parameters: the period $\mathrm{T}$ and the velocity amplitude $\mathrm{U}_{\mathrm{A}}$ of the flow.

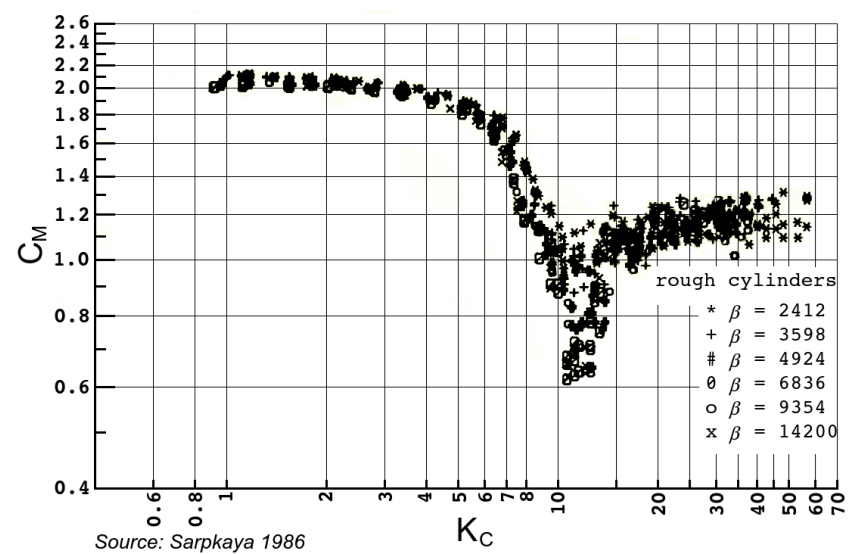

Fig. 6. Comparison of inertia coefficient $C_{M}$ for six rough cylinders, $k_{r} / D=50$. Source: Sarpkaya [2]

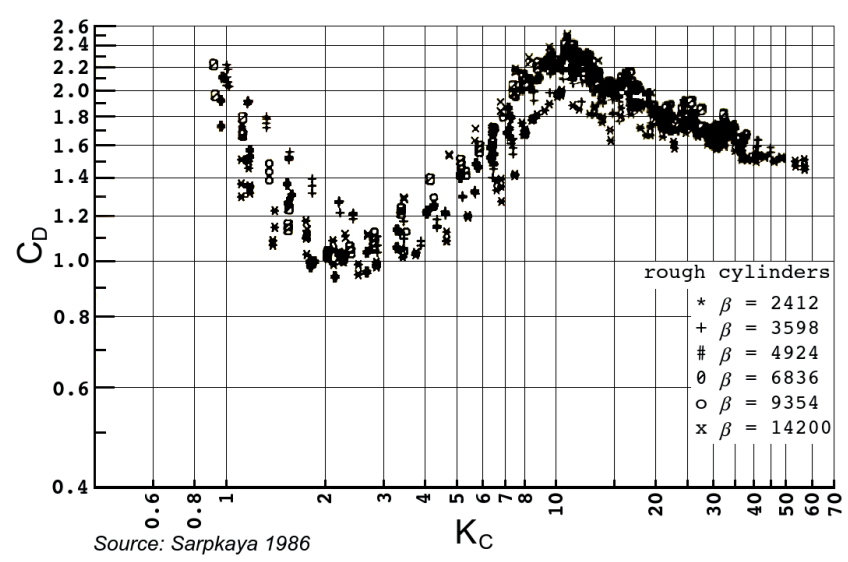

Fig. 7. Comparison of drag coefficient $C_{D}$ for six rough cylinders, $k_{r} / D=50$. Source: Sarpkaya [2]

\section{THE RANGE OF CALCULATIONS}

Due to the fact, that the main objective of this work is to determine the maximum hydro dynamical loads acting on the supporting structure, the coefficients $\mathrm{C}_{\mathrm{M}}$ and $\mathrm{C}_{\mathrm{D}}$ will be calculated for a range of parameters resulting from the spectrum of waves and sea current for the 50 -year storm on the marine area of a depth of $40 \mathrm{~m}$. The calculations were performed for the following set of data:

$\mathrm{T}=6 \mathrm{~s} ; 8 \mathrm{~s} ; 10 \mathrm{~s} ; 12 \mathrm{~s} ; \mathrm{UA}=0.5 \mathrm{~m} / \mathrm{s} ; 1 \mathrm{~m} / \mathrm{s} ; 2 \mathrm{~m} / \mathrm{s}$.

The calculations were performed for both smooth and rough walls. In total, the results were obtained for $\mathrm{C}_{\mathrm{M}}$ and $\mathrm{C}_{\mathrm{D}}$ at 24 calculation points. Roughness caused by the presence of marine growth was taken as $\mathrm{k}_{\mathrm{r}}=100 \mathrm{~mm}$, as recommended by NORSOK $\mathrm{N}-003$ [3]. Relative roughness, $\mathrm{k}_{\mathrm{r}} / \mathrm{D}$ dependent on the length of the diagonal element varies from 0.0025 to about 0.017 .

\section{PARAMETERS USED FOR CALCULATIONS WITH CFD - THE “TECHNICAL” MODEL}

Technical parameters of the computational grid are included in the Table 1. Figure 8 shows a general view of the domain of computations. The calculations were carried out in full scale. 
Tab. 1. Grid parameters

\begin{tabular}{|l|c|c|}
\hline & Smooth surface & Rough surface \\
\hline $\begin{array}{l}\text { Number of control } \\
\text { volumes }\end{array}$ & 676570 & 6303391 \\
\hline Thickness of 1st layer & $0.003 \mathrm{~mm}$ & $1 \mathrm{~mm}$ \\
\hline $\begin{array}{l}\text { Number of layers of } \\
\text { boundary control } \\
\text { volumes }\end{array}$ & 8 & 20 \\
\hline
\end{tabular}

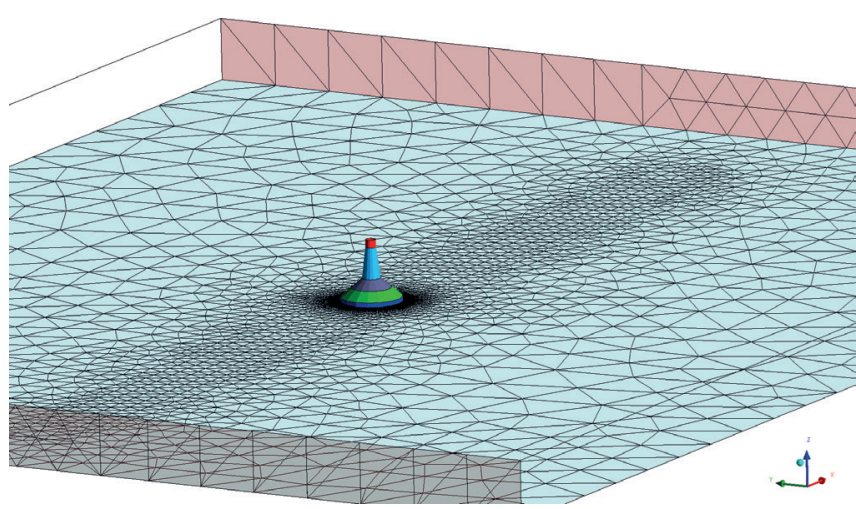

Fig. 8. The computational grid arrangement. View of the inlet/outlet and the bottom of the domain

The differences between the meshes in the case of calculation of smooth and rough structure (Table 1) are the result of turbulence models that were taken and relate mainly to the size of the elements on the surface of the structure and its boundary layer. Thickness of elements of $1^{\text {st }}$ layer, in the case of a smooth structure, takes considerably lower values.

For the smooth surface k- $\omega$ SST turbulence model was employed, for which the thickness of elements of the $1^{\text {st }}$ (boundary) layer (in this case $0.003 \mathrm{~mm}$ ) should be such that the parameter Y+ obtains values close to one.

The rough structure calculations were made on the basis of the $\mathrm{k}-\xi$ turbulence model, with scalable wall function. In this model, the viscous sublayer is omitted, and the logarithmic velocity profile is reduced by the value of $\Delta \mathrm{B}$ that depends on the "grain size" $k_{r}$ (Figure 9).

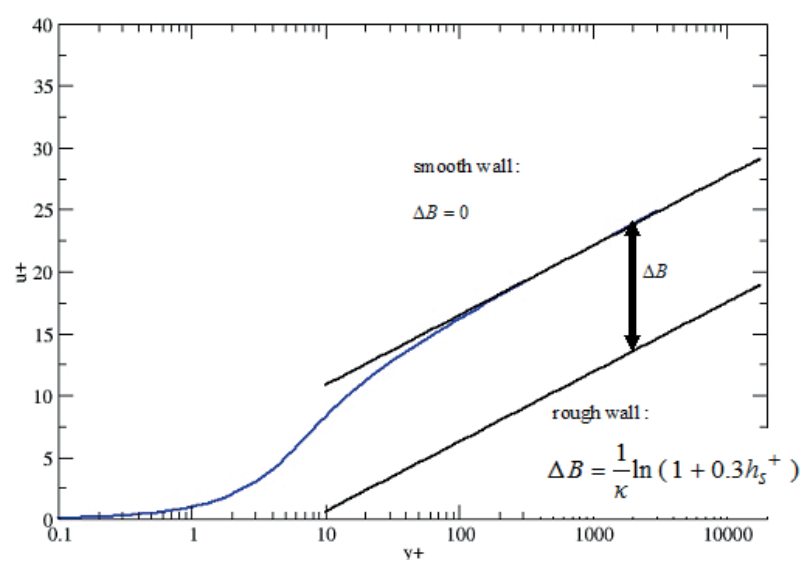

Fig. 9. Wall function for rough surface [5]

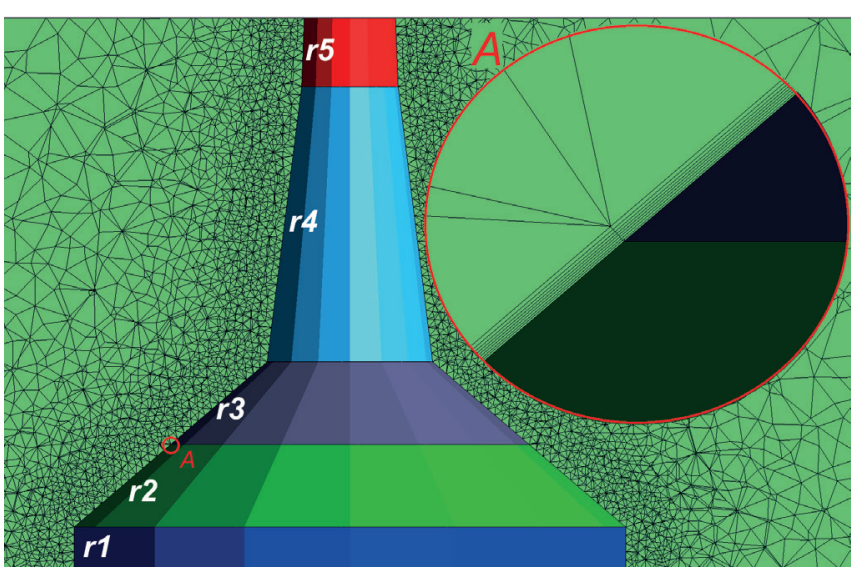

Fig. 10. Grid arrangement around surface of modelled structure. The figure also shows the numbering of segments (regions) $r 1, r 2, r 3, r 4, r 5$

\section{THE RESULTS OF THE CFD CALCULATIONS}

As a result of the CFD calculations, graphs of hydro mechanical forces were obtained that can be induced on specific segments as a function of time (Figure 11). Based on these charts, values of the $C_{M}$ and $C_{D}$ coefficients were determined.

Flow visualization was also obtained in the form of streamlines, based on which, it is possible to conclude that the flow around r1, r2 and r3 was three-dimensional.

The results of the calculations are depicted in diagrams of $\mathrm{C}_{\mathrm{M}}\left(\mathrm{K}_{\mathrm{C}}\right)$ and $\mathrm{C}_{\mathrm{D}}\left(\mathrm{K}_{\mathrm{C}}\right)$, additionally showing the value of the parameter $\beta$ (Figure 13, 14 - smooth surface, Figure 15,16 rough surface)

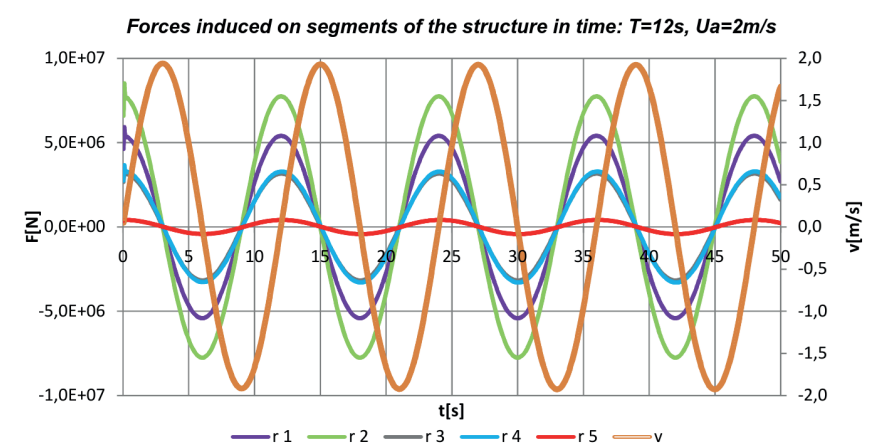

Fig. 11. Forces induced on segments of the support structure in time, for the following data: $T=12 \mathrm{~s}, U_{A}=2 \mathrm{~m} / \mathrm{s}$.

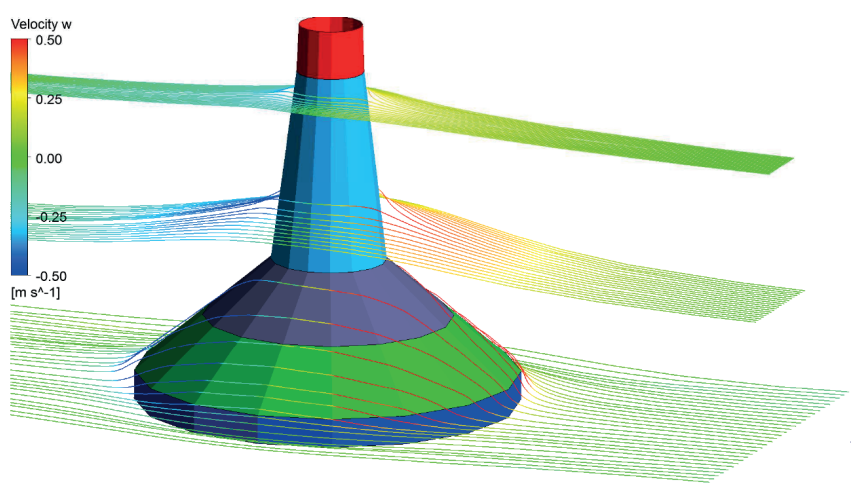

Fig. 12. Streamlines around support structure 


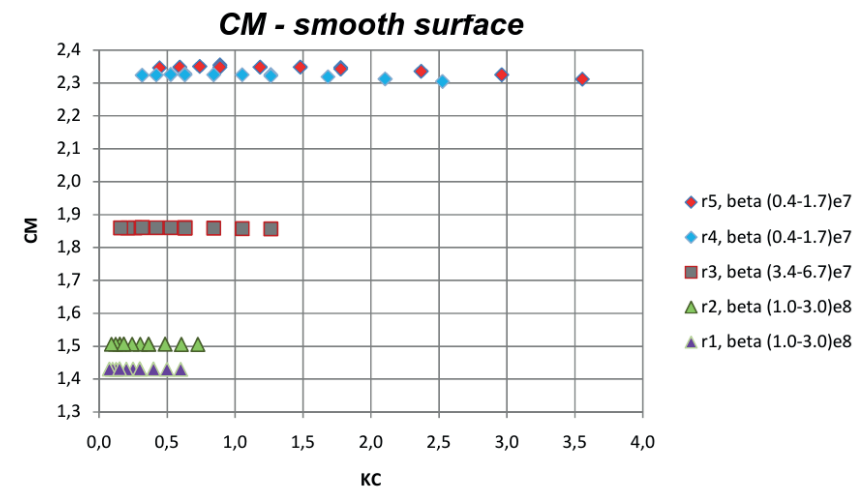

Fig. 13. A graph of the $C_{M}$ as a function of $K_{C}$ for the subsequent segments of the structure. Smooth surface

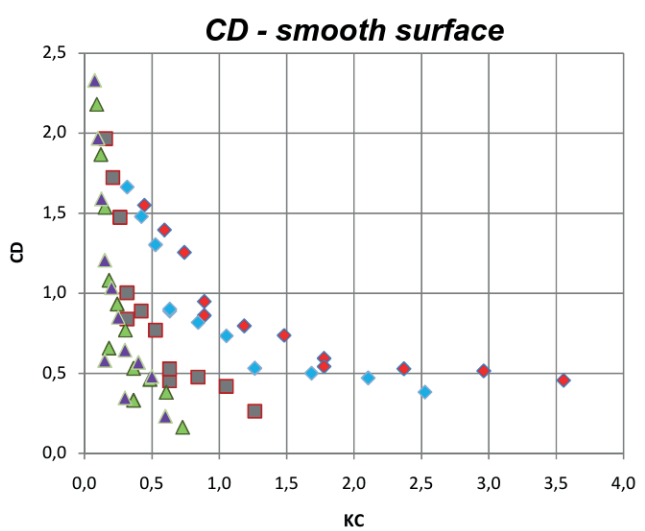

$\mathrm{r} 5$, beta $(0.4-1.7) \mathrm{e} 7$ $\mathrm{r} 4$, beta $(0.4-1.7) \mathrm{e} 7$ $\mathrm{r} 3$, beta $(3.4-6.7) \mathrm{e}$ $\Delta \mathrm{r}$, beta $(1.0-3.0) \mathrm{e} 8$ Ar1, beta (1.0-3.0)es

Fig. 14. A graph of the $C_{D}$ as a function of $K_{C}$ for the subsequent segments of the structure. Smooth surface

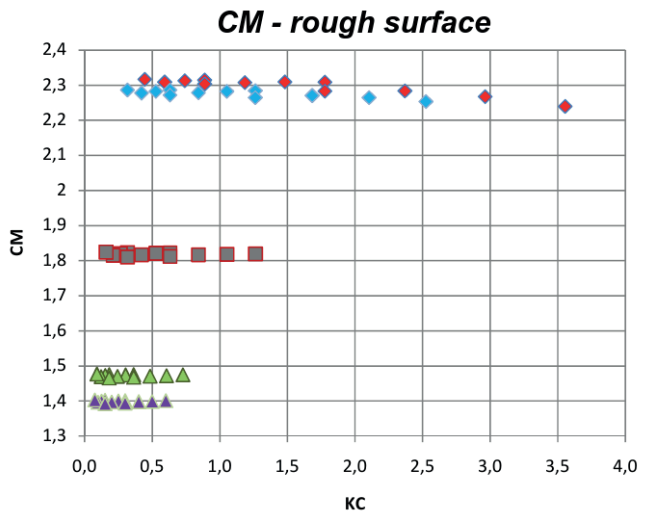

$\bullet \mathrm{r} 5$, beta $(0.4-1.7) \mathrm{e}$ $\leadsto \mathrm{r} 4$, beta $(0.4-1.7) \mathrm{e} 7$ $\square \mathrm{r} 3$, beta $(3.4-6.7) \mathrm{e} 7$ $\Delta \mathrm{r} 2$, beta $(1.0-3.0) \mathrm{e}$ $\Delta \mathrm{r} 1$, beta (1.0-3.0)e8

Fig. 15. A graph of the $C_{M}$ as a function of $K_{C}$ for the subsequent segments of the structure. Rough surface

$C D$ - rough surface

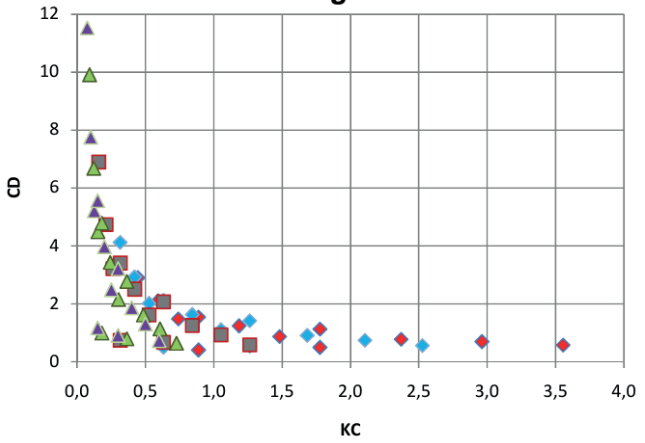

r5, beta $(0.4-1.7) \mathrm{e}$ $\checkmark \mathrm{r} 4$, beta $(0.4-1.7) \mathrm{e} 7$ $\square$ r3, beta (3.4-6.7)e 7 $\Delta r 2$, beta (1.0-3.0)e8 $\mathrm{r} 1$, beta $(1.0-3.0) \mathrm{e}$

Fig. 16. A graph of the $C_{D}$ as a function of $K_{C}$ for the subsequent segments of the structure. Rough surface

\section{ANALYSIS OF THE RESULTS OF CALCULATIONS OF $\mathrm{C}_{\mathrm{M}}$ AND C $_{\mathrm{D}}$}

The resulting characteristics of $C_{M}$ and $C_{D}$ for a smooth surface have a waveform consistent with similar results obtained experimentally for a cylindrical shape. The shape of the curve of $\mathrm{C}_{\mathrm{M}}$ factor for rough structure is almost identical to the plot for the smooth construction.

As expected, the force coefficients for $\mathrm{r} 1, \mathrm{r} 2$ and $\mathrm{r} 3$ segments are lower than that retrieved from the test of cylindrical shape, since the flow around such elements is three-dimensional and thus fluid particles pass by the "obstacle" on the trajectory shorter than in the case of $2 \mathrm{D}$ flow.

The characteristics of the drag coefficient for the rough construction seem unlikely. Perhaps the resistance is strongly overestimated for $\mathrm{K}_{\mathrm{C}}<0.5$ (the differences are significant with respect to the results of model tests [1]). It can be seen, that the applied method of modelling of roughness is not accurate enough.

\section{THE CALCULATION OF THE HYDRO DYNAMICAL FORCES ACTING ON THE SUPPORTING STRUCTURE SUBJECTED TO THE ACTION OF IRREGULAR WAVES AND CURRENT}

\section{SELECTION OF COEFFICIENTS OF HYDRO DYNAMICAL FORCES}

Based on the results of the CFD calculations and the known experimental results $[1,2]$, the following hydro dynamical force coefficients were identified for each item.

Factor $\mathrm{K}_{\mathrm{C}}$ was calculated for the "representative" regular wave with the period of $\mathrm{T}=11.30 \mathrm{~s}$ and height $\mathrm{H}_{\mathrm{s}}=9.01 \mathrm{~m}$, which corresponds to peak period and the significant height of the 50 -year storm in this sea area.

Tab. 2. Selection of the force coefficients based on the flow parameters and the geometry of the structure

\begin{tabular}{|c|c|c|c|c|c|c|c|c|c|}
\hline Segment & $z_{0}[m]$ & $z_{1}[m]$ & $D_{0}[m]$ & $D_{1}[m]$ & $U_{a}(z)[m / s]$ & $K_{C}$ & $\beta$ & $C_{M}$ & $C_{D}$ \\
\hline $\boldsymbol{r} \mathbf{1}$ & -40 & -37 & 40 & 40 & 1.29 & 0.36 & $1.19 \mathrm{E}+08$ & 1.4 & 1.0 \\
\hline $\boldsymbol{r} \mathbf{2}$ & -37 & -31 & 40 & 26 & 1.32 & 0.45 & $8.09 \mathrm{E}+07$ & 1.5 & 1.0 \\
\hline $\boldsymbol{r} \mathbf{3}$ & -31 & -25 & 26 & 12 & 1.41 & 0.84 & $2.68 \mathrm{E}+07$ & 1.8 & 1.0 \\
\hline $\boldsymbol{r} 4$ & -25 & -5 & 12 & 7 & 1.83 & 2.18 & $6.71 \mathrm{E}+06$ & 2.3 & 1.0 \\
\hline $\boldsymbol{r} \mathbf{5}$ & -5 & $5(15)$ & 7 & 6.25 & 2.82 & 4.80 & $3.26 \mathrm{E}+06$ & 2.3 & 1.0 \\
\hline
\end{tabular}

The value of the amplitude of the velocity was calculated for $\mathrm{z}=0.5\left(\mathrm{z}_{0}+\mathrm{z}_{1}\right)$ using the linear (Airy's) wave model:

$$
U_{a}(z)=\frac{\pi H_{w}}{T} \frac{\cosh [k(z+d)]}{\sinh (k d)}
$$

Keulegan-Carpenter number is defined as $\mathrm{K}_{\mathrm{C}}=\mathrm{U}_{\mathrm{a}} \mathrm{T} / \mathrm{D}$, while the $\beta$ number is calculated as $[1]: \beta=\mathrm{D}^{2} /(v \mathrm{~T})$. The inertia coefficient $C_{M}$ was read from the Figure 15. Based on Figure 16 and the value of $K_{C}$, it was assumed, that the drag coefficient $\mathrm{C}_{\mathrm{D}}$ for each segment is approximately 1.0. 


\section{CALCULATION OF HYDRO DYNAMICAL RESPONSE}

The wave spectrum with the parameters described in subsection 3.4 corresponds to the storm duration of 3 hours. For this spectrum three wave functions were randomly chosen - all of one hour duration. For 1-hour realization of the wave not to be a periodic phenomenon, about 1200 terms of the series given by eq. (11) and (12) are required [6]. Additionally, the calculations took into account the presence of the sea current with parameters described above.

The results of calculations for the wave at which the maximum load of the construction was observed are shown below. Figure 17 shows the height of the free surface in the axis of symmetry of the structure as a function of time, whereas Figure 18 shows a resultant horizontal force acting on the structure. The bending moment relative to the bottom of the structure $(\mathrm{z}=-40 \mathrm{~m})$ is shown in Figure 19. It was assumed, that the maximum load is such, that the bending moment of the construction reaches its maximum. For the results presented here, the maximum stress occurs at time $\mathrm{t}=3450.5 \mathrm{~s}$.

For this time step, the distribution of hydro dynamical loads acting on the construction was shown on Figure 20. Loads depicted in the graph are due to the action of hydro dynamical forces that are associated with movement of fluid $\mathrm{F}=\mathrm{F}(\mathrm{U}(\mathrm{t}), \partial \mathrm{U}(\mathrm{t}) / \partial \mathrm{t})$. To these forces the hydro statistic load resulting for the seawater and the ballast located within the gravity base structure, as well as the thrust and torque of the wind turbine (transmitted through the column), weights and other forces must be added.

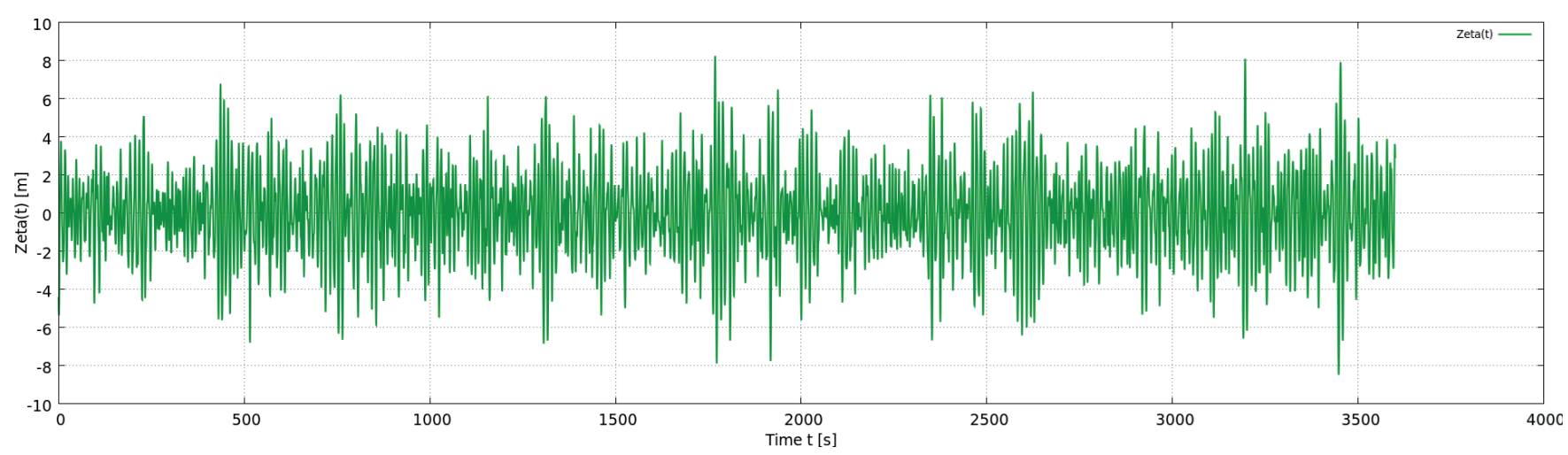

Fig. 17. The free surface level $\varsigma$ in the symmetry axis of the structure in time domain

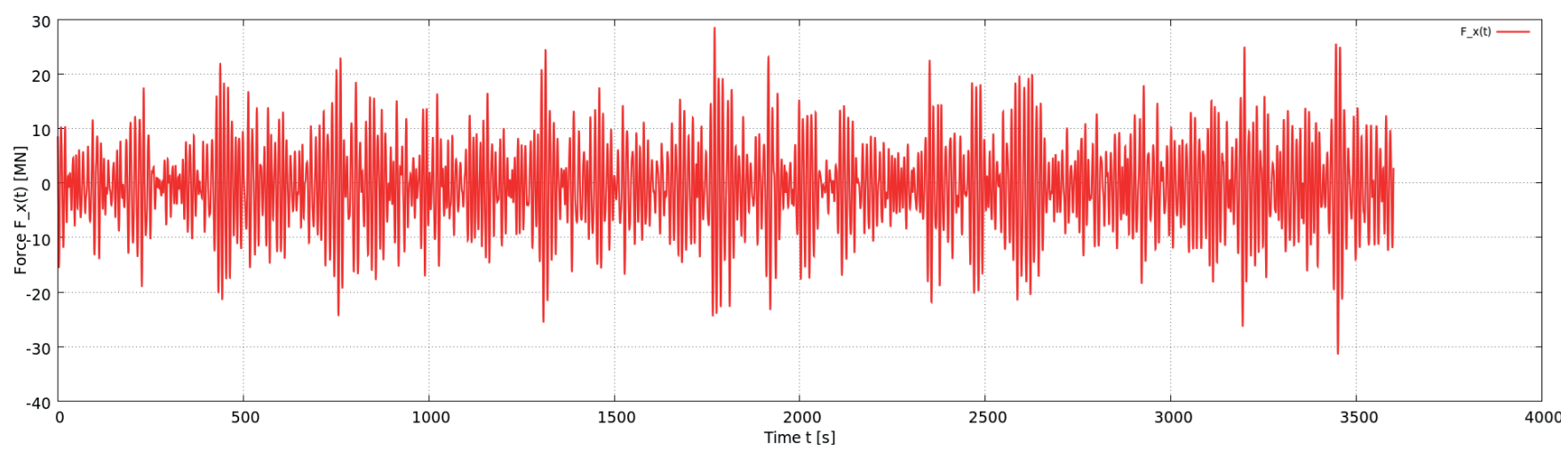

Fig. 18. The total force in the $x$-direction $F_{x}$ induced on the structure by the wave and current

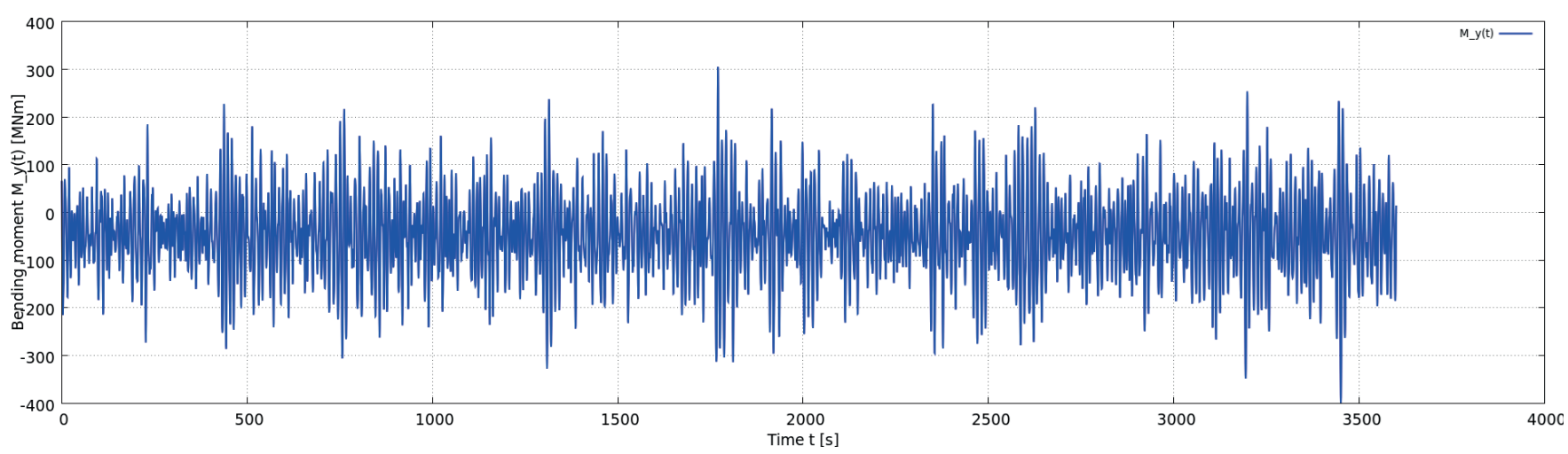

Fig. 19. The total bending moment $M_{y}($ at $z=-40 \mathrm{~m})$ induced on the structure by the wave and current 

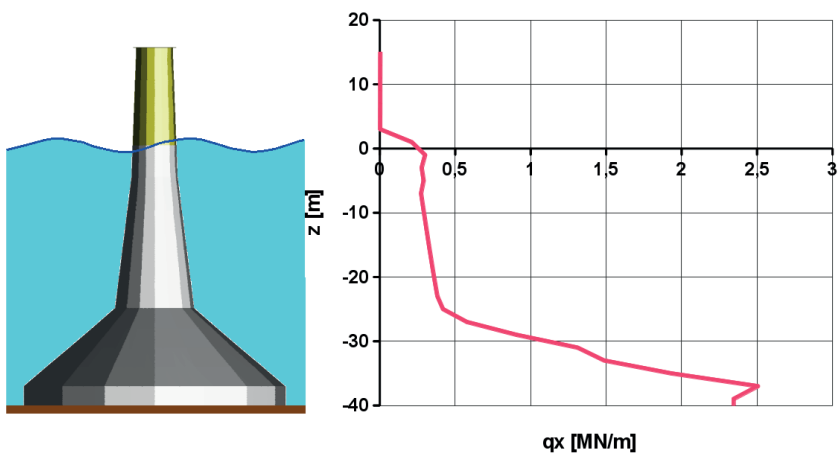

Fig. 20. Distribution of continuous load $q_{x}$ due to sea wave and current as a function of $z$ for the time step $t=3450.5 \mathrm{~s}$ (maximum value of bending moment)

\section{SUMMARY AND CONCLUSIONS}

In this article we presented a method for calculating unsteady loads acting on supporting structure for offshore wind turbines. The method is based on the expanded use of Morison equation and coefficients of the forces obtained from computations with modern CFD software - ANSYS CFX.

Based on the results of CFD analysis of segments of similar shape to a cylindrical, it was found, that the forces coefficients are close to the values obtained experimentally by Sarpkaya $[1,2]$.

Through to the simplified approach, one can effectively define construction loads of initial design, (assuming that small changes in the geometry do not significantly affect the values of the coefficients $C_{M}$ and $C_{D}$ ). Determination of the sequence of loads for wave lasting (in reality) three hours with the time step of $1 / 2 \mathrm{~s}$ takes about 1 to 3 hours of computing time.

These loads will be used for the design of structural elements based on FEM analysis. The methodology of FEM analysis for similar structure was presented by Żywicki et al [11].

\section{ACKNOWLEDGMENT}

CFD analysis has been performed with ANSYS-CFX solver. Calculations were carried out at the Academic Computer Center in Gdańsk (TASK).

This research was supported by The Polish National Centre for Research and Development (NCBR) under the project PBS1/A6/8/2012 "AQUILO".

\section{REFERENCES}

1. Sarpkaya T.: Wave forces on offshore structures, Cambridge University Press, 2010

2. Sarpkaya T.: In-line and transverse forces on smooth and rough cylinders in oscillatory flow at high Reynolds numbers, Monterey, California. Naval Postgraduate School, 1986
3. Recommended Practice DNV-RP-C205: Environmental conditions and environmental loads, Det Norske Veritas, October 2010

4. Levis E.V.: Principles of Naval Architecture. Vol. III Motions in Waves and Controllability, SNAME, 1989

5. ANSYS CFX - Solver Theory Guide, ANSYS Inc., October 2012

6. Chakrabarti S.K.: Hydrodynamics of Offshore Structures, WIT Press / Computational Mechanics, 2003

7. Kamphuis J.W., Introduction to Coastal Engineering and Management, Advanced Series on Ocean Engineering: Volume 30, 2010

8. Li F., van Gelder P.H.A.J.M., Ranasighe R., Callghan D.P., Jongejan R.B., Probabilistic modelling of extreme storms along the Dutch coast, Coastal Engineering 86, 2014

9. WAMDI Group: The WAM model - A Third Generation Ocean Wave Prediction Model. J. Phys. Oceanography, 18, 1988

10. Cieślikiewicz W., Paplińska-Swerpel B.: A 44-year hindcast of wind wave fields over the Baltic Sea, Coastal Engineering 55, 2008

11. Dymarski C., Dymarski P., Żywicki J.: Design and strength calculations of the tripod support structure for offshore power plant POLISH MARITIME RESEARCH 1(85) 2015 Vol. 22; pp. 36-46 10.1515/pomr-2015-0006

\section{CONTACT WITH AUTHOR}

$$
\text { Paweł Dymarski }
$$$$
\text { Ewelina Ciba }
$$

Gdańsk Univeristy of Technology Faculty of Ocean Engineering and Ship Technology 11/12 Narutowicza St. 80-233 Gdańsk

Poland

\section{Tomasz Marcinkowski}

Maritime Institute in Gdansk

Długi Targ 41/42

80-830 Gdańsk

Poland 